\title{
Osteoid Osteoma of Distal Phalanx of Little Finger.
}

Amit Joshi ${ }^{1}$, Nirab Kayastha ${ }^{1}$.

${ }^{1}$ Department of Orthopedics, Shree Birendra Hospital.

\begin{abstract}
Osteoid Osteoma is benign bone forming tumor commonly occurs in lower limbs. Osteoid Osteoma of upper limb is rare, and it is extremely rare in hands. We report a case of a 20 year old male who presented with complaints of pain in nail bed of left little finger over a period of one year with gradually increasing swelling and deformity of nail. Radiological examination revealed a well-defined lytic lesion with sclerotic margin at distal phalanx with a nidus at center. Curettage and removal of nidus was done under digital nerve block. He was symptom free from next day of surgery and the tip of the finger has significantly regained its original shape over a period of two years. The aim of this paper is to report yet another uncommon case of osteoid Osteoma located at distal phalanx of little finger.

Keywords: little finger, phalangs, osteoid osteoma.
\end{abstract}

\section{INTRODUCTION}

Osteoid Osteoma is uncommon bone forming benign tumor of bone accounting nearly $3 \%$ of all bone neoplasm ${ }^{1}$. The most frequent location of osteoid Osteoma is long bones of lower limb, where it occurs in more than $50 \%$ of cases $^{2}$. According to the literature, involvement of upper limb is rare and osteoid Osteoma affecting the hand is even rarer accounting only $5-8 \%$ of all osteoid osteoma ${ }^{3}$. Within the hand also, it is mostly reported in proximal phalanx. Osteoid Osteoma of distal phalanx of little finger is extremely rare and rarely reported ${ }^{4-7}$. The aim of this case report is to present a case of osteoid Osteoma of distal phalanx of little finger.

\section{CASE REPORT}

A 20 years old male patient presented with complaints of pain in left little finger over a period of one year. He described pain as stabbing in nature, aggravated by touch and pressure. Pain was worse at night, which was partially relived by analgesics. For last two months, the pain become worse, and was not responding to analgesics. The patient didn't give any history of trauma or infection of the little finger. On examination, there was clubbing of little finger (Figure 1), the whole of the distal phalanx was increased in size giving a drumstick appearance. The nail was larger in comparison to normal side and hypertrophic. The little finger was warmer, however there so no dilated capillaries. While pressing and tapping the nail with fingers, it caused excruciating pain over the little finger and whole of the upper limb. The range of motion of inter phalangeal joint was painful and slightly reduced. There were no regional lymphadenopathies and other fingers were normal.

Radiograph (Figure 2. A and B) revealed an osteolytic lesion with well-defined sclerotic margin and a sclerotic nidus at the center of the lytic lesion. On lateral view the lesion was more on the dorsal side of the distal phalanx, with sclerosis and enlargement of whole of the distal phalanx.

A diagnosis of osteoid Osteoma was made on the basis of clinical and radiological features. Other base line investigations were within normal limits.

Under ring block and digital tourniquet the lesion was completely excised after removing nail with curettage and nidus removal. Histopathological examination report confirmed the diagnosis of Osteoid Osteoma. The postoperative period was uneventful and the pain completely disappeared from the very next day. The patient was followed up for two years after surgery. During this year he has no recurrence of pain and the size and the shape of the little finger has also improved significantly. A recent X- Ray also showed healed lesion of distal phalanx (Figure 3).

\section{Correspondence:}

Lt. Col. Dr. Amit Joshi

Department of Orthopedics, Shree Birendra Hospital.

Kathmandu, Nepal.

Email: dramitjoshi7@gmail.com

Phone: +977-9841233850 


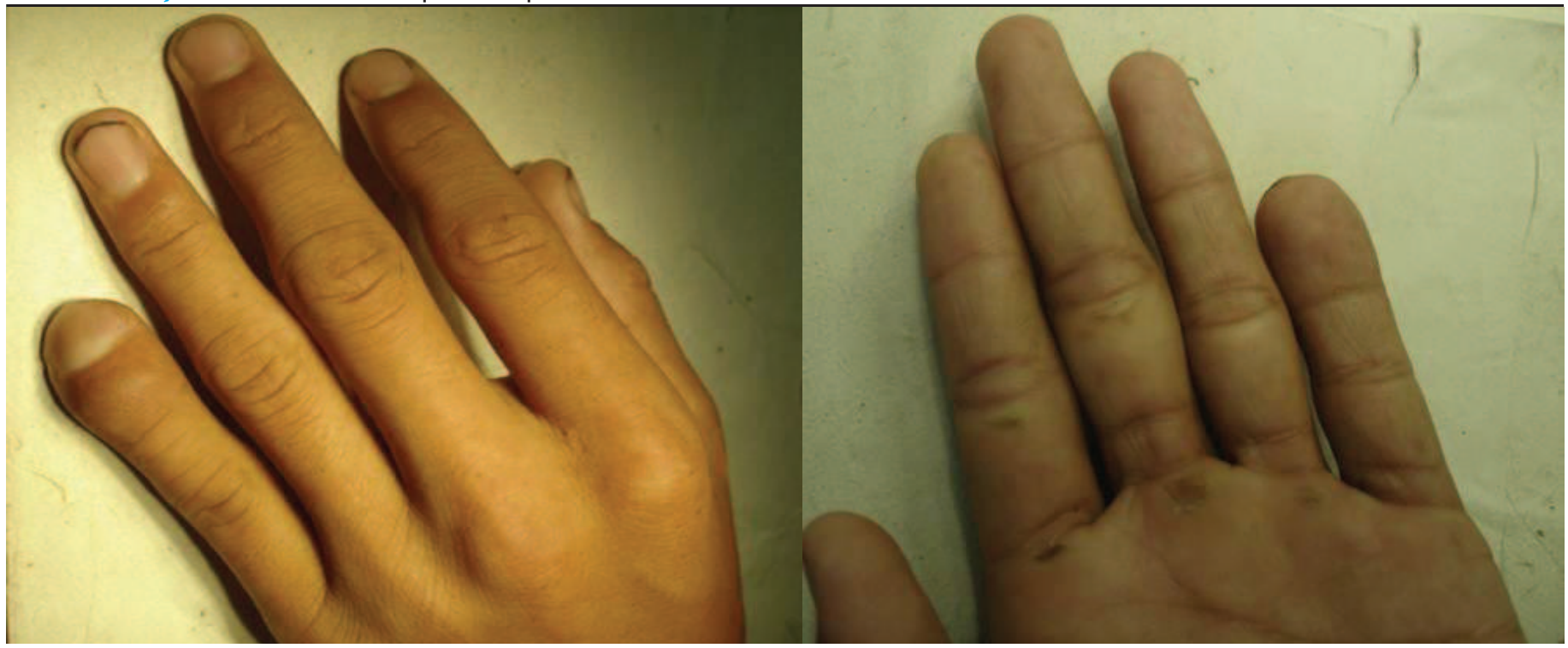

Figure 1. Clinical appearance of little finger
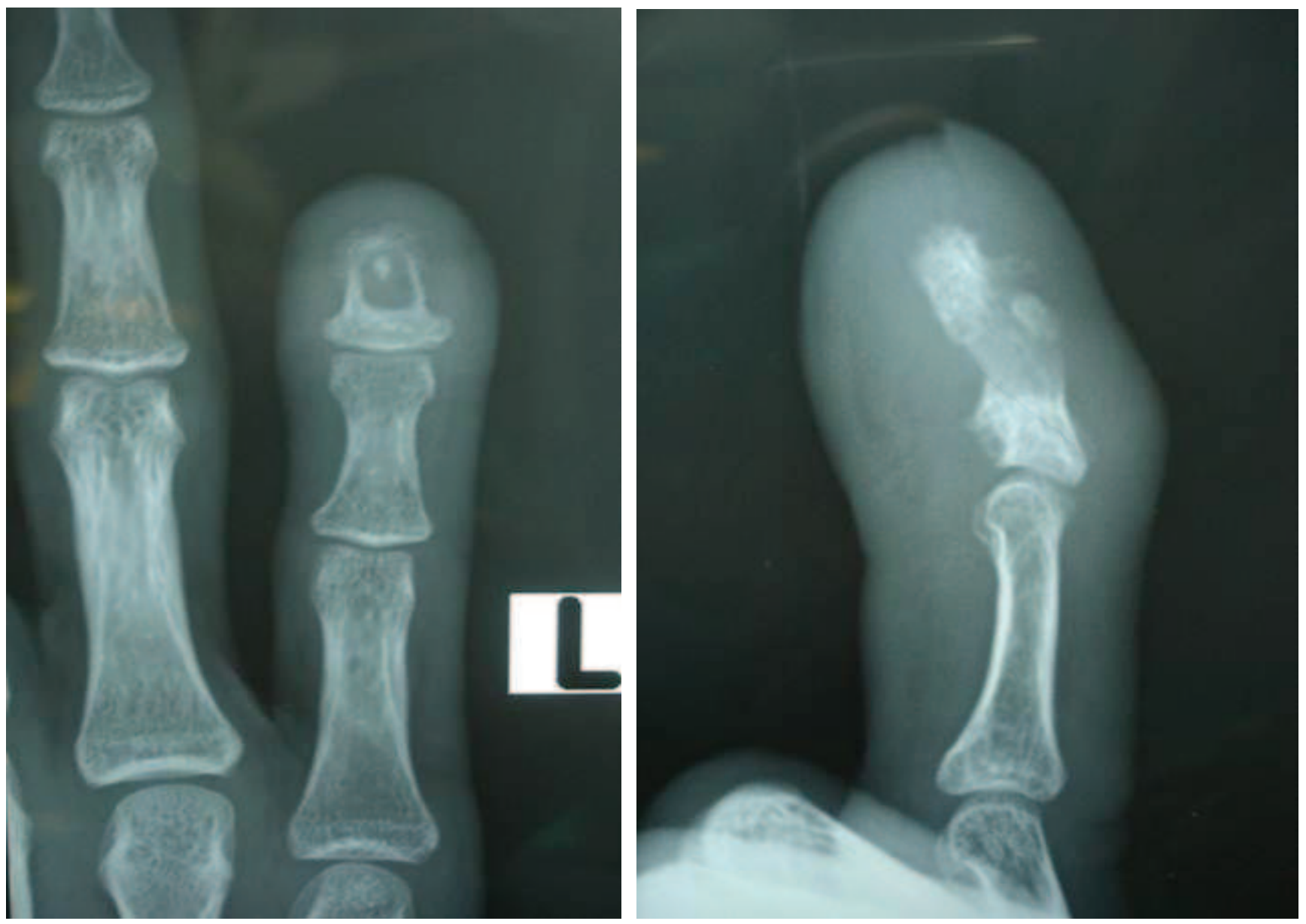

Figure 2. Plain radiograph with lytic lesion and Nidus

Osteoid Osteoma, a bone forming benign tumor, accounts

\section{DISCUSSION AND REVIEW} LITERATURE. for $10-12 \%$ of all benign bone tumors. The incidence of Osteoid Osteoma is highest in second decade with tendencies to occur more in male ${ }^{8-10}$. More than $50 \%$ of 


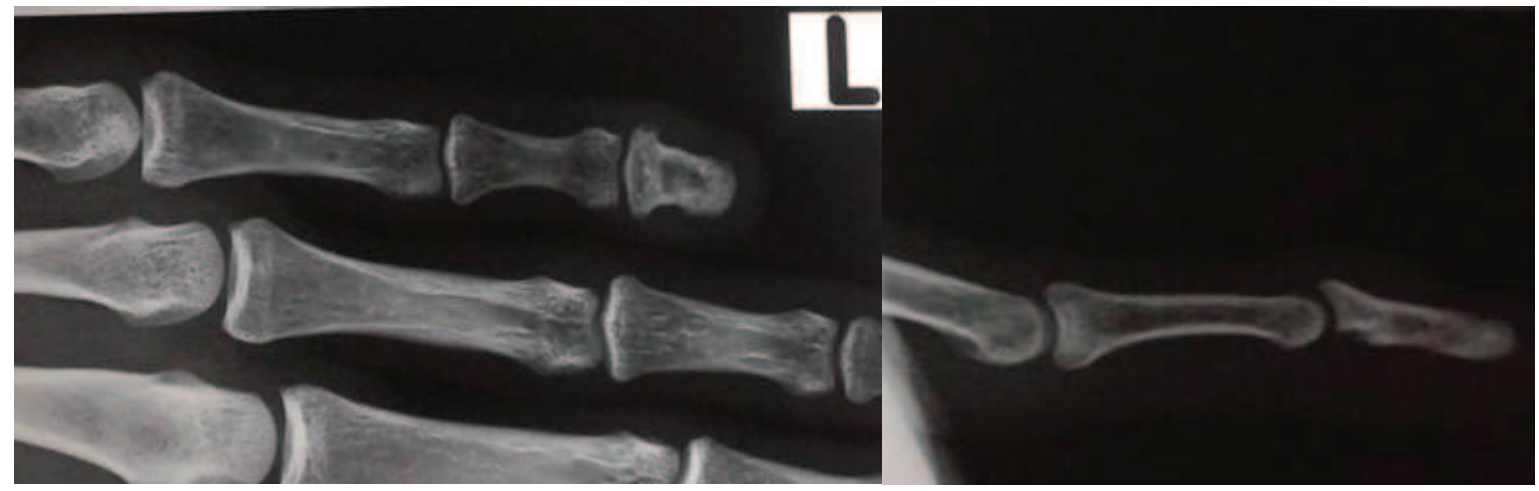

Figure 3. 2 Years follow up X-Ray.

Osteoid Osteoma occurs in femur and tibia ${ }^{7-10}$. Its incidence in fingers and toes are about 3-6\% and 2-3\% respectively. In relation to the location in bone, Osteoid Osteoma is classified in to three types: Cortical, intramedullary and Sub-periosteal ${ }^{11}$. Cortical type Osteoid Osteoma is the commonest; these are frequently seen in tibia and femur. Unicortical thickening with solid type of periosteal reaction is the commonest radiological picture of cortical Osteoid Osteoma. Intramedullary Osteoid Osteoma is frequently seen in juxta-articular regions, and bones of hands and feet are frequent locations. our case also could be classified as intramedullary Osteoid Osteoma. As we could see the cortex are very well defined in both AP and lateral views (Figure 1). Sub periosteal types are characterized by soft tissue lesion with virtually no bony reactions and the diagnosis is usually delayed up to HPE.

Since Jaffee first reported Osteoid Osteoma in 1935, the lesion was identified almost in all bones of the body. Involvement of small bones of hands reported rarely. Although Osteoid Osteoma of distal phalanx were already reported but distal phalanx of little finger has not been reported previously. This paper is reporting an Osteoid Osteoma of distal phalanx of little finger.

Classically, Osteoid Osteoma presents with progressive pain usually at night and temporarily relived by analgesics. Phalangeal lesions also have similar presentation in most of the cases. Our patient was also having pain for around one year, which gradually increased in intensity and become less nonrespondant to analgesics, which actually made the patients to seek medical help. Phalangeal lesion may lead to clubbing of the finger and nail hypertrophy are more corelated with distal phalanx lesion ${ }^{12,13}$. Our patient also had clubbing of the finger and the nail was hypertrophied. Other presentations that have been reported are profuse sweating in the finger tip or intense autonomic nervous phenomena mimicking peripheral neuropathy ${ }^{5,14}$. The clubbing and other phenomenon are attributed to increased vascularity in the tissue adjacent to the Osteoid Osteoma 15,16. Previous report has shown that the nail and size of phalanx gradually returns to normal, as occurred in our patient.

In majority of patients plain radiographs are diagnostic. The typical tumor comprises a small radiolucent lesion less then one $\mathrm{Cm}$ in diameter. A nidus is usually detected centrally within the radiolucency. The radiological differential diagnosis of Osteoid Osteoma arising in a terminal phalanx includes sub-acute infection, osteoblastoma, epidermoid cyst and glomous tumors. In our patients also, we had glomous tumor in our mind, as the lesion was having pin point tenderness. But radiologically the nidus was so evident that Osteoid Osteoma was the choice of diagnosis (Figure 2). Sometimes when clinical features and radiological findings are un equivocal MRI, CT and even bone scan has been advised. We didn't do these investigations as the clinical and the radiological pictures were classic of Osteoid Osteoma.

When lesion is difficult to assess or when surgery is associated with high morbidity, conservative treatment with NSAIDS has been recommended ${ }^{17}$. But whenever possible, most of the literatures suggest surgical excision of the lesion. In most of the instances surgery is curative and provides immediate and permanent relief of pain $^{18}$. Our patient also had undergone curettage of the lesion with removal of nidus. Patient was followed up for two years and he was symptom free. Recurrences have been reported by some authors if the nidus is not completely removed ${ }^{13}$. Kransdorf reported that some patient may experience a symptom free period following an unsuccessful surgery but that may last only for 1 year ${ }^{13,20}$. Our patient was symptom free for two years and on consecutive check X-Rays the nidus was not present and the lytic lesion healed (Figure 3).

In conclusion, Osteoid Osteoma of distal phalanx is not common but should be considered in differential diagnosis of painful swelling of fingertip. Plain radiograph and classic clinical presentation is usually diagnostic. Surgery is still 
the treatment of choice for phalangeal osteoid Osteoma because of their easy access.

1. Becce F, Theumann N, Rochette A, et al. Osteoid osteoma and osteoid osteoma-mimicking lesions: biopsy findings, distinctive MDCT features and treatment by radiofrequency ablation. Eur Radiol. 2010;20:2439-46.

2. Ramos L, Santos JA, Santos G, Guiral J. Radiofrequency ablation in osteoid osteoma of the finger. J Hand Surg Am. 2005;30(4):798-802.

3. Boriani S, Capanna R. Osteoid osteoma of the hand. Review of literature and case report. Chir Organi Mov. 1979;65(5):555-60.

4. Foucher G, Lemarechal P, Citron N, Merle M. Osteoid osteoma of the distal phalanx: a report of four cases and review of the literature. J Hand Surg Br. 1987;12(3):382-6.

5. Nakatsuchi Y, Sugimoto Y, Nakano M. Osteoid osteoma ofthe terminal phalanx. J Hand Surg Br. 1984;9(2):201-3.

6. Grundberg AB. Osteoid osteoma of the thumb: report of a case. J Hand Surg Am. 1977;2(4):266.

7. Levy Y, Rosenheck S, Greiff M, Torok G. Osteoid osteoma of the distal phalanx of the thumb. Acta Orthop Scand.1979 Dec;50(6 Pt 1):667-9.

8. Meng QF. Phalangeal osteoid osteoma. Br J Radiol. 1989;62:321-5.

9. LaCroix ML, Thomas JR, Nicholas RW. Subperiosteal osteoid osteoma of the distal phalanx of the fourth toe. Orthopedics. 2001;24:695-6.
10. Wierks C, Lomasney LM, Demos TC. Diagnosis: osteoid osteoma. Orthopedics. 2004;27:1205-8.

11. Liu YC, Hsu MC, Lin ZI. Unusual and complicated areas of juxtaarticular osteoid osteoma: a report of two cases. J Orthop Surg ROC. 2006;23:51-6.

12. Sproule JA, Khan F, Fogarty EE. Osteoid osteoma: painfulenlargement of the second toe. Arch Orthop Trauma Surg. 2004;124:354-6.

13. 4. Barca F, Acciaro AL, Recchioni MD. Osteoid osteoma ofthe phalanx: enlargement of the toe: two case reports. Foot Ankle Int. 1998;19:388-93.

14. Giannikas A, Papachristou G, Tiniakos G et al. Osteoid osteoma of the terminal phalanges. Hand .1977;9(3):295-300.

15. Rosborough D. Osteoid osteoma. Report of a lesion in the terminal phalanx of a finger. J Bone Joint Surg Br. 1966;48(3):485-7.

16. Inagaki $H$, Inoue G. Osteoid osteoma of the distal phalanx. Orthopedics. 1999;22(11):1093-4.

17. Kneisl JS, Simon MA. Medical management compared with operative treatment for osteoid osteoma. J Bone Joint Surg Am. 1992;74(2):179-85.

18. La Croix ML, Thomas JR, Nicholas RW. Subperiosteal osteoid osteoma of the distal phalanx of the fourth toe. Orthopaedics. 2001;24(7):695-6. 19. Wu KK. Osteoid osteoma of the foot. J Foot Surg. 1991;30(2):190-4. 20. Kransdorf MJ, Stull MA, Gilkey FW, Moser RP Jr. Osteoid osteoma. Radiographics. 1991;11(4):671-96. 